Daniel, E.I, Garcia, D, Marasini, R., Kolo., S, Oshodi, O. (2019). "Improving Construction Management Practice in the Gibraltar Construction Industry ." In: Proc. 27th Annual Conference of the International. Group for Lean Construction (IGLC), Pasquire C. and Hamzeh F.R. (ed.), Dublin, Ireland, pp. 539-550. DOI: https://doi.org/10.24928/2019/0227. Available at: 〈www.iglc.net>.

\title{
IMPROVING CONSTRUCTION MANAGEMENT PRACTICE IN THE GIBRALTAR CONSTRUCTION INDUSTRY
}

\author{
Emmanuel I. Daniel1, Daniel Garcia², Ramesh Marasini ${ }^{3}$, Shaba Kolo ${ }^{4}$, and \\ Olalekan Oshodi ${ }^{5}$
}

\begin{abstract}
Research has shown that $57 \%$ of activities in a construction project is non-value adding (waste) which contributes to the poor performance of the sector. While other countries of the world such the USA, UK, Brazil, Nigeria and Israel among others are seeking to understand this challenge and deploy innovative ways and modern techniques to improve it, limited studies have explored factors that contribute to non-value adding activities (NVA) in the Gibraltar construction industry. The current study aims to identify the factors that contribute to NVA on construction sites in Gibraltar and to present an outlook on how this could be minimised using Last Planner System(LPS).

A combination of quantative and qualitative research approaches were used. Thirtyone questionnaire responses were analysed and seven semi-structured interviews were conducted. The investigation reveals that the development of unrealistic schedules, lack of adequate training, delayed approval process and work interruption due to the community are the key factors that contribute to NVA. The study found that the suggestions offered by construction professional for minimising NVA align with some LPS principles. The study concludes that some of the current practices, could serve as justification for the introduction of LPS in the construction sector of Gibraltar.
\end{abstract}

\section{KEYWORDS}

Last planner system, non-value adding activities, waste, workflow, Gibraltar.

\footnotetext{
${ }^{1}$ Lecturer, Department of Construction Management and the Built Environment, Solent University, Southampton. UK. emmanuel.daniel@solent.ac.uk

${ }^{2}$ BSc(Hons) Graduate, Department of Construction Management and the Built Environment, Solent University, Southampton, UK. dangarcia.official@gmail.com

3 Associate Professor, Department of Construction Management and the Built Environment, Solent University, Southampton. UK. ramesh.marasini@solent.ac.uk

4 Lecturer, Department of Construction Management and the Built Environment, Solent University, Southampton. UK. shaba.kolo@solent.ac.uk

5 Post-Doctoral Research Fellow, University of Johanesburge, South Africa. os.oshodi@gmail.com
} 


\section{INTRODUCTION}

The construction industry is characterised with low productivity. In the existing literature, it was revealed that productivity has been growing at $1 \%$ every year and the efficiency of workers is about $40 \%$ in the construction sector (Prabhu \& Ambika, 2013). The common causes of low producitivity include mismanagement of construction materials, design errors, communication problems and inexperience of project team members, among others (Dai et al., 2007; Naoum, 2016). Based on the causes of low productivity, it is evident that poor management of site activities and pre-construction phase are the main reasons for low productivity.

While other countries of the world such the USA, UK, Brazil, Nigeria and Israel are seeking to understand this challenge and deploy innovative and modern management techniques such as Lean Construction, Building Information Modelling,and Offsite Construction to minimise wasteful processes (Khosrowshahi and Arayici,2012), the situation in Gibraltar is yet to be known. Gibraltar is a British Overseas Territory with a population of 34,571 people (Worldmeter, 2019). The Ministry for the Environment Government of Gibraltar report (2013) confirms that the waste in the Gibraltar construction industry is difficult to measure. The wastes considered in the report include both physical and process wastes. There is a lack of studies that explore factors contributing to wasteful processes (non-value adding activities) in the Gibraltar construction industry.

The term "non-value adding activities (NVA)" and "waste" is used interchangeably in this study. Waste in this study is limited to process waste. This study aims to identify the factors that contribute to non-value adding activities (waste) on the construction sites in Gibraltar and to present the prospect of minimising it through the use of Last Planner System (LPS). The LPS is a lean construction technique that focuses on supporting the flow of work through the project, builds trust and collaboration with a workforce and delivers a task safely (Ballard, 2000). From studies, the implementation of lean construction techniques such as the LPS has positive outcomes in construction process improvement and minimise waste (Fernando-Solis et al., 2012; Alarcon et al., 2011).

\section{LITERATURE REVIEW}

\section{LeAN CONSTRUCTION AND THE CONCEPT OF WASTE}

Waste in construction is defined in various ways. From a lean construction perspective, waste is any process that incurs a cost but does not add value to the project (Koskela, 2000). Waste occurs as a result of overproduction, waiting, inventory, defect, movements, processing and transportation (Alarcon, 1997; Shingo, 1998). Abdelrazig (2015) identified three more categories of waste which are time, people and bureaucracy.

Waste is also referred to as NVA and is defined as an "activity that takes time, resources or space but does not add value to a project" (Zhao \& Chua, 2003). According to Koskela, (2000) value-adding activities convert material and information to the output which is required by the customer. Zhao and Chua, (2003) found that NVA is usaually influence by the work environment factors and project related factors. Examples of the 
project related factors are project features, design features among others while example of work environment features include equipment condition, sequencing, information among others. Additionally, Koskela, (2000) identified three factors that contribute to NVA which include; the structure of the production system, the way the production is controlled and the nature of the production system. All these shows the importance of paying attention to the designing of the production system so as to minimise the incidence of NVA on site.

However, only limited activities in the construction industry are value adding. Nagapan et al., (2012); Zhao and Chua, (2003) found that non-value adding activities could arise from poor site management, lack of adequate training, inadequate planning, unrealistic schedules, mistakes and errors in design, mistakes during construction, incompetent subcontractor, rework and lack of coordination between parties. Diekmann et al. (2004) found from their study that $57 \%$ of activities in the construction industry is NVA; $33 \%$ support activity and $10 \%$ value adding. However, in the manufacturing sector, $62 \%$ of activities are value adding. This emphasises the need for the construction industry to improve by minimising NVA using an innovative approach like lean construction. Ingle and Waghmare (2015), found that the implementation of lean techniques in construction projects reduces the wastes generated from the traditional construction practices.

\section{LAST PLANNER SYSTEM}

The Last Planner System (LPS) is a technique within lean construction that focuses on supporting a smooth workflow through the development of collaborative relationship among project stakeholders (Ballard and Tommelein, 2017; Daniel et al., 2017; Ballard \& Zabelle, 2000). The LPS consist of twelve interrelated principles (Ballard and Tommelein, 2016). Rusell et al., (2015); Gonzalez et al., (2010); Wambeke et al., (2011) found that the LPS supports the development of a reliable plan, reduce variation in a project, improve project performance because of its integrated approach. However, it should be noted that the benefits of LPS can only be achieved by utilising the main components in the LPS technique, which consists of master scheduling, phase scheduling, lookahead planning, weekly work planning (WWP), measurement and learning (Ballard and Tommelein, 2016).

Lindhard and Wandahl (2013) claim that the master schedule consists of uncertain variables, owing to the unpredictable the nature of a construction processes. However, this identifies the activities that should be accomplished and reveals milestones within a project (Ballard \& Howell, 1994). Phase scheduling is known to be the "link between work structuring and production control" (Ballard \& Howell, 2003). It ensures a thought through sequence and structure of work with different trades (Ballard \& Zabelle, 2000)

The look-ahead and make-ready planning process identifies and removes constraints to the planned task sufficiently before its execution. The look-ahead planning is usually done within the 6 - 8 weeks window. The make-ready element focuses on ensuring smooth workflow during production activities on site by ensuring the identified constraints are removed (Koskela, 2000). However, Daniel et al., (2017) found that there seems to be a reluctance in implementing make-ready planning during the LPS implementation. 
The WWP aims to identify scheduled commitments that would be completed the subsequent week, which creates an efficient workflow on projects (Koskela, 1999). It ensures only activities that are well sized, sequenced and sound are sent into the work phase. The last and the most crucial element of the LPS is measurement and learning. The measurements of percent plan complete (PPC) and the investigation of the reason for non-completion of tasks provide learning and improvement opportunity for the team on the project (Ballard, 2000). Learning in the LPS is made possible because production planning and production control form an integrated approach.

\section{RESEARCH METHOD}

A mixed research design that uses quantitative and qualitative approaches was adopted for the study. The quantitative method allowed research participants to rate the factors that contribute to NVA in the context of Gibraltar construction industry. A questionnaire survey was adopted as it enables the study to reach a large number of participants (Naoum, 2013). In addition, the interviews were used to collect the views and opionions of the research participants on the effective ways of minimizing NVA that they observed whilst working in Gibraltar rather than relying on information available in literature alone (Creswell, 2007).

\section{RESEARCH DESIGN}

A review of literature was done to identify the factors responsible for NVA. These factors were used to develop the survey instrument. The 11 factors that contribute to NVA identified from the literature review include; poor site management, lack of adequate training, inadequate planning, unrealistic schedules, mistakes and errors in design, mistakes during construction, incompetent sub-contractor, rework and lack of coordination between parties (Nagapan et al., 2012). Furthermore, to understanding the current practice that shows some resemblance with the LPS principles in Gilbrater, the concept of Last Planner Thinking introduced in Daniel et al, (2014) was used. According to Daniel et al, (2014), Last Planner Thinking are practices that show some resemblance with some of the LPS principles which could serve as a platform for implementing the LPS. Some of these practices include having weekly site meetings, identification of constraints, having coordination meetings among others (Daniel et al., 2014). The survey was designed with three sections. Section one focused on the background information of the respond2ents. Section two sort to identify how the eleven factors contribute to NVA in the Gibraltar construction industry on a five-point Likert scale. In section three, the respondents were asked to rate how often the identified Last Planner Thinking practice was observed in construction sites in Gibraltar. An open-ended semi-structured interview was used to gather evidence on how the NVA observed on the construction sites in Gibraltar could be minimised.

\section{Data Collection ANd Analysis}

The questionnaire was hosted online for three months using the SurveyMonkey®. The link was emailed to the prospective respondents and placed on other social media platforms meant for construction professionals in Gibraltar. According to $\mathrm{HR}$ 
Government of Gibraltar (2017), the population of the contruction industry was 3,407. Based on this, a sample size calculator was used to determine the sample size for the study. With a confidence level of $90 \%$ and a margin of error of $10 \%$, the sample size was determined to be Sixty-seven. However, it is important to note that over half of the population are frontier workers (HR Governement of Gibraltar, 2017). Thirty-one responses were received from the questionnaire survey and this represented over $45 \%$ of the sample size. Seven semi-structured interviews were conducted and this number was deemed to be sufficient as no new issues were emergeing after seven interviews which meant data saturation could have been attained (Francis et. al., 2010). The focus of the interview was to enable the respondent shed light on how the identified NVA could be minimised. The quantitative data were analysed using SPSS (V 23.0.0.0) while the qualitative data were analysed using thematic analysis. The participants who took part in the study included: project managers, directors, estimators, architects, construction managers, engineers, quantity surveyors and site managers, which shows the diverse range of professionals working in the construction industry in Gibraltar and justifies the validity of the study.

\section{RESULTS AND DISCUSSION}

\section{RESPONDENT BACKGROUND INFORMATION}

The respondents surveyed consisted of '29\% Construction Managers', '23\% Quantity Surveyors', '19\% Project Managers', '13\% Site Managers', ‘3\% Technical Officer', ‘3\% Chief Operations Officer', '3\% Electrical Sub-contractor' and '3\% Engineers'. The results suggest that the responses received cut across the relevant stakeholders who are involved in analysing the performance of a project and decision making on a day-to-day basis on a project. Furthermore, majority of the respondent have over 10 years experience in the construction industry. This showed the respondents have a sufficient experience in the construction industry in Gibraltar, and thus their response would be reliable.

\section{FACTORS THAT CONTRIBUTE TO NON-VALUE ADDING ACTIVITIES ON CONSTRUCTION SITE IN GibRALTAR}

The results, as shown in Table 1, revealed the three top factors as: 'unrealistic schedules with a weighted average of 1.87', 'lack of adequate training with a weighted average of 2.19 ' and 'a delayed approval process with a weighted average of 2.45'. Mcgevna (2012) argues that scheduling is one of the most critical aspects of planning in a project. This means the introduction of the Last Planner System into the Gibraltar construction industry could minimise the most contributing factor to NVA currently observed on construction sites. According to Russell et al., (2015); Wambeke et al., (2011) and Ballard, (2000), the implementation of LPS focuses on reducing uncertainty which is inherent in the traditional approach to project management. There is a concensus that all the factors listed in Table 1 contribute to NVA on construction sites in Gibraltar, suggesting that considerations should be given to all 11 NVA factors.

Furthermore, the respondents identified a lack of adequate training as the second topmost factor which contributes to non-value adding activities (Waste). This factor was 
expected to have a high contribution in the beginning of the study, as Gibraltar's construction industry consists of cross-employment between Spain and unqualified workers. Contractors adopt this strategy in order to reduce labour costs in a project. However comparing this finding with previous studies on factors that contributes to NVA (Nagapan et al., 2012; Daniel et al., 2014), interruption from the local seems to be peculair to the Gilbrater construction industry. This shows the need to pay attention to social value delivery in construction projects.

Table 1: Ranking of Factors that Contribute to NVA on Construction site in Gibraltar

\begin{tabular}{llcl}
\hline \multicolumn{1}{c}{ Contributing Factors to NVA } & Frequency & $\begin{array}{l}\text { Weighted } \\
\text { Average }\end{array}$ & Ranking \\
\hline 'Unrealistic schedule' & 31 & 1.87 & 1 \\
'Lack of training' & 31 & 2.19 & 2 \\
'Delayed approval process' & 31 & 2.45 & 3 \\
'Work interruption due to community' & 31 & 2.58 & 4 \\
'Poor site layout' & 31 & 2.65 & 5 \\
'Miscommunication between the workforce' & 31 & 2.71 & 6 \\
'Disagreements between contractors & 31 & 2.71 & 7 \\
subcontractors and client' & 31 & & 8 \\
'Lack of resources' & 31 & 2.73 & 9 \\
'Lack of team work' & 31 & 2.74 & 10 \\
'Delay payment' & 31 & 2.77 & 11 \\
'Lack of flow in construction' & & 2.84 & \\
& & & \\
\hline
\end{tabular}

Social value is what a community receives from an organisation from the execution of its business (Hunter, (2014). Conversely, when the organisation fails to give back to the community it could lead to conflict. Daniel and Pasquire, (2019) argued that construction organisations should consider the local community around their project as customers, this would enable them to be commited to improve the quality of life of the community around the project.

\section{LAST PLANNER THINKING IN THE GIBRALTAR CONSTRUCTION INDUSTRY}

To understand the concept of Last Planner Thinking in the context of Gilbralter, the respondents were required to identify current Last Planner Thinking practices on a five points Likert scale where one is very often and five is never. The study found that the 'identification of constraints' before any task is commenced and the 'holding of weekly coordination meetings' are common practices. This finding aligns with a similar study conducted in Nigeria where a weekly meeting was also reported to be observed often (Daniel et al., 2014). However, the occurrence of weekly meetings observed in both studies may be primarily due to its inclusion in the traditional contract. It could be argued that such weekly site meetings may not necessarily serve as a platform for collaboration as expected in the Last Planner System and are used for a limited scope.

Traditionally, weekly site meeting is more of an opportunity for subcontractors to receive instructions rather than make input into the decisions. Foley and Macmillan (2005) found that during a team meeting the input from subcontractors is only $2 \%$. It is 
no surprise therefore, as shown in Figure 1, the managers rarely allow subcontractors to make input during the decision-making process in the Gibraltar construction industry. This is a dominant practice in the traditional approach to project management.

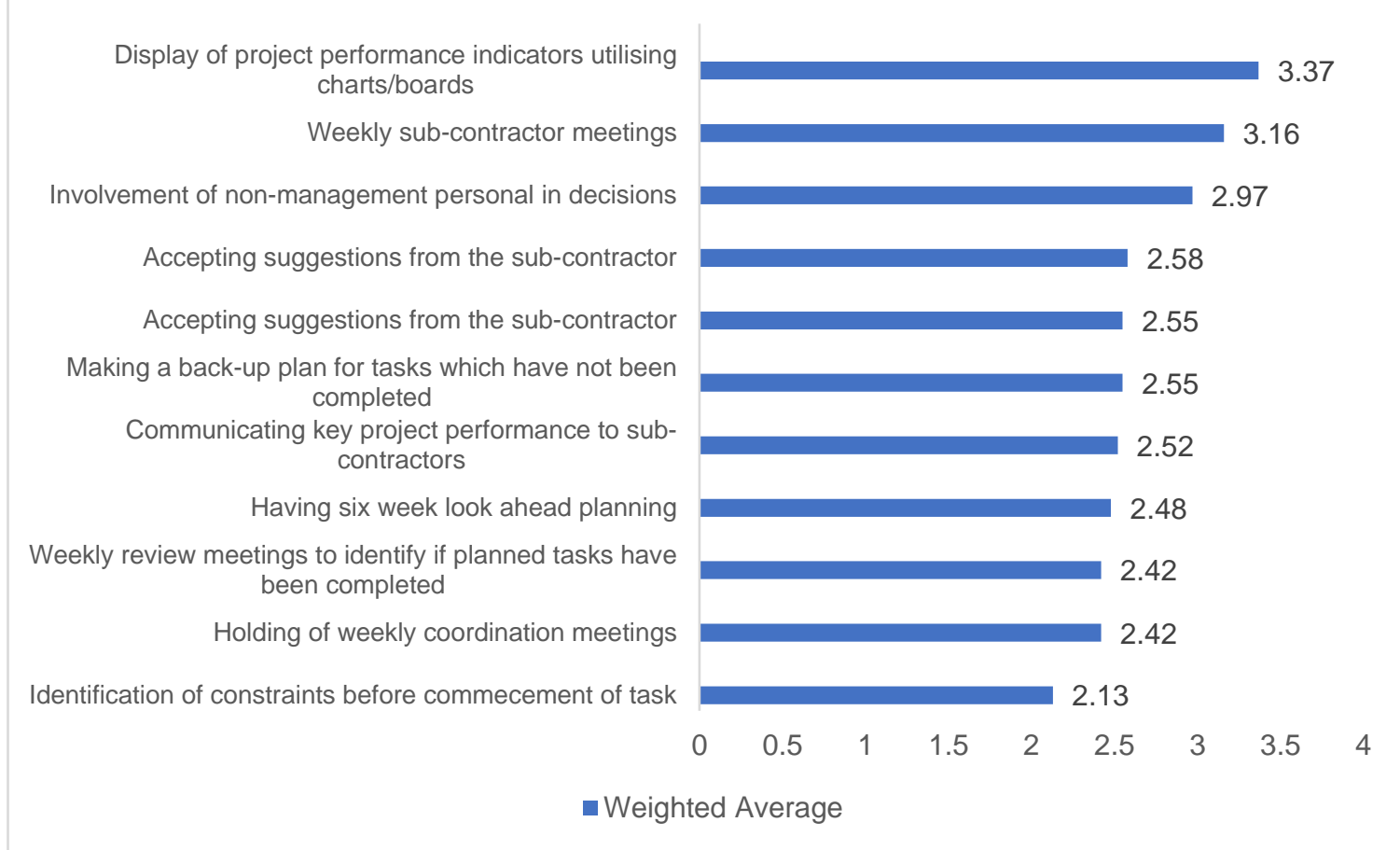

Figure 1 indicates some Last Planner Thinking within the Gibraltar construction industry.

In contrary, the LPS empowers the project stakeholders to make a promise of what they can do during the WWP (Ballard, 2000). While the current weekly site meeting may not necessarily follow the LPS principles completely, it could serve as a platform to implement LPS WWP principles. Furthermore, the practice of identification of constraint before the commencement of a task could serve as a foundation for make-ready planning practice in implementing the LPS in Gibraltar. The make-ready process enables the team to collaboratively identify constraint and implement a strategy for eliminating the constraint for a smooth workflow (Ballard and Tommelein, 2017).

The results highlight that 'display of project performance indicators', 'weekly subcontractor meetings' and 'involvement of non-management personnel in decision making' are the three least practised on sites in Gibraltar. This indicates there is no much collaboration between the sub-contractor and management which could negatively influence the implementation of the core principles of the LPS in the construction sector of Gibraltar. One of the core principles of the LPS is to allow the people who would do the work to be involved in the planning (Ballard and Tommelein, 2017). The noninvolvement of the subcontractors in the decision and planning process would defeat the purpose of implementing the LPS. The current practice in Gibraltar could have been influenced by culture (Temple, 2016). Studies have shown that culture is an important 
issue to consider in the implementation of lean generally and the implementation of the LPS in particular (Johansen and Porter, 2003). In implementing the LPS in the Gibraltar construction industry, significant attention should be given to the cultural issues such as the outright sidelining of subcontractors from the decision making process on site.

\section{How to Minimise Non-Value-Adding Activities on Construction SITE IN GIBRALTARGIBRALTER}

The respondents were asked to suggest how non-value adding activities (Waste) could be minimised in Gibraltar's construction industry. Figure 2 shows the emerging themes from the analysis. It is evident that in addition to pre-planning and adequate training, most of the suggestions revolved around developing an active communication network and collaboration with the different stakeholders in the project. Some of the respondents stated that: "In Gibraltar, proper training, planning ahead and communications between all parties involved in the projects would help to deliver the project effectively" [R05 Construction Director]"Allow all parties to meet regularly to discuss any occurrences that may be stopping the project from evolving" [RO1 Project Manager] "Continued progress and coordination meetings with management/subcontractors and site foreman working hands in hands, so informaion has less of a chain to feed back to the workers"[R04 Electrical subcontractor]

Again, all these shows the central role clear communication and active collaboration plays in minimising NVA on a construction project.

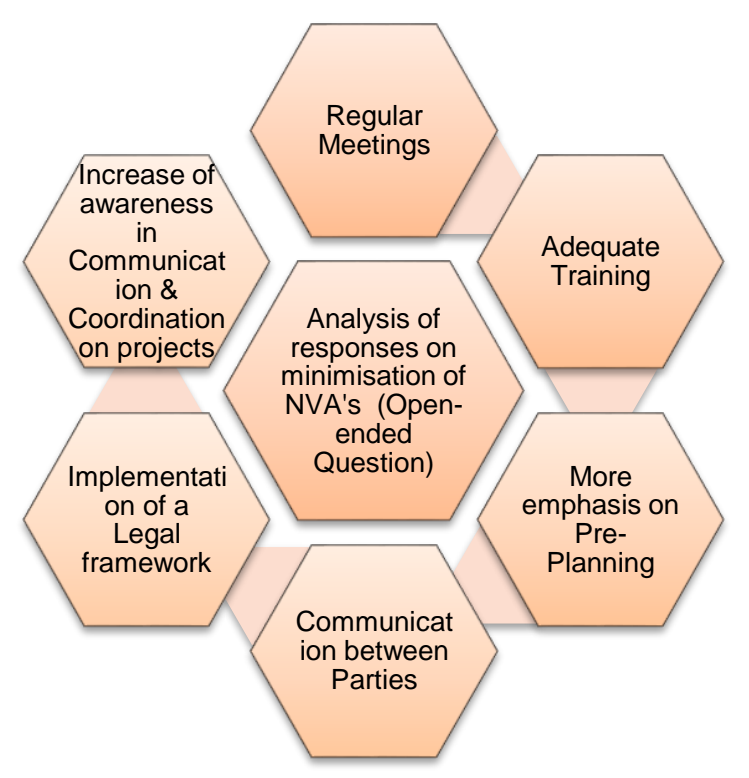

Figure 2: How to Minimise Non Value Adding Activities on Construction site in Gibraltar

Construction management researchers have consistently argued communication breakdown between the various stakeholders on a project is one of the major contributors 
to project failure (Murray et al., 2007). For instance, poor communication between the construction manager, work package contractors and the client was responsible for both cost and time overrun in the case between Great Eastern Hotel and John Laing (Donohoe and Brooks, 2007). However, the LPS supports the development of collaborative conversation among different stakeholders on a construction project which supports effective and clear communication in a complex project environment (Rusell et al., 2015; Gonzalez et al., 2010). Arguably, the application of the LPS principles has the potential to address some of the suggestions for minimising NVA in Gilbrater made by the respondents as shown in Figure 2. For instance, the phase planning, lookahead planning, WWP and measure and learning in the LPS could address issues such as 'more emphasis on pre-planning' and 'regular meeting', project coordination' and communication between parties. This implies the use of the LPS could minimise the incidence of NVA in the Gibraltar construction industry. However, some of the respondent also believed that focusing on the critical activities would enable them develop reliable programmes. One of the respondent stated that : "Identifying the critical activities would support the development of a clear and concise program"'[R07 Construction Manager]. This view is contrary to the priciples of Last Planer System where the focus is in understanding the interface between the different stakeholders that would be doing the work. This could mean the traditional approach is the dominant practice among the construction practitioners in the Gibraltar construction industry.

\section{CONCLUSIONS}

The current study aimed to identify the factors that contribute to non-value adding activities (waste) on the construction sites in Gibraltar and to present an outlook on how this could be minimised through the Last Planner System. The study found that the topmost factors that contribute to NVA in the Gibraltar construction industry include the development of unrealistic schedules, lack of adequate training, delayed approval process and work interruption due to the community. Although the factors that contribute to NVA in Gibraltar is not entirely different from those reported from other countries, the interruption from the local communities seems to be peculiar to Gibraltar construction context and this shows the need to pay attention to social value delivery in construction projects.

The investigation found that there are practices within the Gibraltar construction industry that mirror the Last Planner System thinking which include identification of constraints before commencement of tasks, having weekly coordination meetings and weekly review meeting. However, the current practice is not only rooted in the traditional approach to project management, but it is also unsystematic. For instance, subcontractor inputs were not considered in such meetings. Nevertheless, the current practice could serve as in route for introducing the LPS into the Gibraltar construction industry.

The study found that the suggestions offered by construction professional in the Gibraltar construction industry for minimising NVA such as an emphasis on pre-planning, regular meeting, better communication with the stakeholders, increase of awareness in communication \& coordination on projects align with some LPS principles. This suggests 
the introduction of LPS has a significant potential to minimise NVA in Gibraltar. However, the top-down approach with the non-involvement of the subcontractor by the management in the decision making is seen as key a barrier. Thus, ways of involving subconratcors in the decision making should be identified and managed effectively during the introduction of the LPS into the Gibraltar construction industry. The current finding is based on the perception of the construction professionals; the actual implementation LPS could reveal more contextual issues in Gibraltar.

\section{REFERENCE}

Alarcon, L., 1997. Lean Construction. Print Edition ed. Rotterdam: A A Balkema

Abdelrazig, Y.E., (2015). Using lean techniques to reduce waste and improve performance in municipal construction project delivery. The University of Texas at Arlington.

Alarcón, L.F., Diethelm, S., Rojo, O. and Calderón, R., 2011. Assessing the impacts of implementing lean construction. Revista ingeniería de construcción, 23(1), pp.26-33.

Ballard G. and Zabelle T. (2000). "Lean Design: Process, Tools, \& Techniques" White Paper \#10, Lean Construction Institute.

Ballard, G. and Howell, G. (1994) Implementing lean construction: stabilizing work flow, in Proceedings of the 2nd Annual Conference of the International Group for Lean Construction, Santiago, Chile.

Ballard, G. and Howell, G., (2004). Competing construction management paradigms. Lean Construction Journal, 1(1), 38-45.

Ballard, H. G. (2000), The Last Planner System of Production Control. PhD. Thesis, University of Birmingham, Birmingham UK.

Creswell, J. (2013). Qualitative inquiry and research design: Choosing among five approaches. Thousand Oaks: SAGE Publications.

Dai, J., Goodrum, P. M., \& Maloney, W. F. (2007). Analysis of craft workers' and foremen's perceptions of the factors affecting construction labour productivity. Construction Management and Economics, 25(11), 1139-1152.

Daniel, E. and Pasquire, C. 2019. Creating social value within the delivery of construction projects: the role of lean approach. Engineering, Construction and Architectural Management.

Daniel, E.I. , Pasquire, C. \& Ameh, O.J. 2014, 'The Magic of the Last Planner® System for Nigerian Construction' In:, Kalsaas, B.T., Koskela, L. \& Saurin, T.A., 22nd Annual Conference of the International Group for Lean Construction. Oslo, Norway, 25-27 Jun 2014. pp 605-616

Daniel, E.I., Pasquire, C., Dickens, G. and Ballard, H.G., (2017). The relationship between the Last Planner® System and collaborative planning practice in UK construction. Engineering, Construction and Architectural Management, 24(3), pp.407-425.

Dave, B., Hämäläinen, J-P., and Koskela, L., (2015). "Exploring the recurrent problems in the Last Planer implementation on construction projects. In: Proc. Indian Lean Const. Conference, Mumbai, India. 
Diekmann, J. E, Krewedl, M., Balonick, J., Stewart, T., and Won, S. (2004) Application of Lean Manufacturing Principles to Construction, Construction Industry Institute, Report No.191

Donohoe, S. and Brooks, L., 2007. Reflections on construction management procurement following Great Eastern Hotel Company v. John Laing. Construction Management and Economics, 25(7), pp.701-708.

Fernandez-Solis, J. L., Porwal, V., Lavy, S., Shafaat, A., Rybkowski, Z. K., Son, K., and Lagoo, N. (2012). "Survey of motivations, benefits, and implementation challenges of last planner system users". Journal of Construction Engineering and Management, 139(4), 354-360.

Foley, J. and Macmillan, S., 2005. Patterns of interaction in construction team meetings. CoDesign, 1(1), pp.19-37.

Francis, J. J., Johnston, M., Robertson, C., Glidewell, L., Entwistle, V., Eccles, M. P., \& Grimshaw, J. M. (2010). What Is an Adequate Sample Size? Operationalising Data Saturation for Theory-Based Interview Studies. Psychology and Health, 25(10), 12291245. doi:10.1080/08870440903194015

González, V., Alarcón, L.F., Maturana, S., Mundaca, F. and Bustamante, J., (2010). "Improving planning reliability and project performance using the reliable commitment model". Journal of Construction Engineering and Management, 136(10), pp.1129-1139.

Halligan, D.W., Demsetz, L.A., Brown, J.D. and Pace, C.B., (1994). Action-response model and loss of productivity in construction. Journal of Construction Engineering and Management, 120(1), pp.47-64.

HM Governemnt Gibraltar (2017). Employment 2017 | Government of Gibraltar. [online] Available at: https://www.gibraltar.gov.gi/new/statistics-topic-area/2017/employment [Accessed 15 Feb. 2019].

Hunter, M. (2014), "Social enterprise is good for design, Design Council".[Online] Available at: http://www.designcouncil.org.uk/news-opinion/social-enterprise-gooddesign [Accessed: 09 March 2017].

Ingle, A. \& Waghmare, A. P., 2015. Advances in Construction: Lean Construction for Productivity enhancement and waste minimization. International Journal of Engineering and Applied Science, 2(11), pp. 19-23.

Khosrowshahi, F. and Arayici, Y., 2012. Roadmap for implementation of BIM in the UK construction industry. Engineering, Construction and Architectural Management, 19(6), pp.610-635.

Koskela, L. J., Stratton, R., and Koskenvesa, A. (2010). "Last Planner and critical chain in construction management: comparative analysis". In Proceedings of the 18th Annual Conference of the International Group for Lean Construction, National Building Research Institute, Technion-Israel Institute of Technology, 538-547

Koskela, L., 2000. An Exploration towards a production theory and its application to construction, Finland: VTT Publications.

Lindhard, S., and Wandahl, S.(2013). Looking for Improvement in the Last Planner System: Defining Selection Criteria. In ICCREM @ Construction and Operation in the Context of Sustainability, 27-35. ASCE. 
McGevna, V., 2012. The Importance of a Realistic Schedule. [Online] Available at: http://www.pmsuccess.com/Articles/Importance_of_Realistic_Schedule.pdf[Accessed 25 April 2018].

Merrell, J. M., 2016. 6 Ways to Leaders Can Improve Employees' Quality of Work and Life. [Online]. Available at: https://workology.com/6-ways-to-leaders-can-improveemployees-quality-of-work-and-life/[Accessed 26 April 2018].

Murray, M., Dainty, A. and Moore, D., 2007. Communication in construction: Theory and practice.London: Routledge.

Nagapan, S., Rahman, I.A., Asmi, A., Memon, A.H. and Zin, R.M., 2012. Identifying causes of construction waste-case of Central Region of Peninsula Malaysia. International Journal of Integrated Engineering, 4(2).

Naoum, S. G. (2016). Factors influencing labor productivity on construction sites: A state-of-the-art literature review and a survey. International Journal of Productivity and Performance Management, 65(3), 401-421.

Naoum, S., 2012. Dissertation research and writing for construction students. London: Routledge.

Prabhu, G. P. \& Ambika, D., 2013. Study on the behaviour of workers in the construction industry to improve production efficiency. International Journal of Civil, Structural, Environmental and Infrastructure Engineering Research and Development, 3(1), pp. 2249-6866.

Russell, M.M., Liu, M., Howell, G. and Hsiang, S.M., (2014). "Case studies of the allocation and reduction of time buffer through use of the last planner system". Journal of Construction Engineering and Management, 141(2), p.04014068.

Shingo, S., 1988. Non-stock production: the Shingo system of continuous improvement. USA: CRC Press.

Temple, G., (2016). Medieval practices in the construction industry. [Online] Available at: http://gibraltarpanorama.gi/14775/243114/a/medieval-practices-in-the-constructionindustry [Accessed 25 April 2018].

Wambeke, B.W., Liu, M. and Hsiang, S.M., 2012. Using last planner and a risk assessment matrix to reduce variation in mechanical related construction tasks. Journal of Construction Engineering and Management, 138(4), pp.491-498.

Woetzel, J., Sridhar, M. \& Mischike, J., 2017. The construction industry has a productivity problem — and here's how to solve it. [Online] Available at: https://www.marketwatch.com/story/the-construction-industry-has-a-productivityproblem-and-heres-how-to-solve-it-2017-03-04 [Accessed 25 April 2018].

Worldmeter, (2019). Population of Gibraltar (2019 and historical). [Online]. [Available at: http://www.worldometers.info/world-population/gibraltar-population/]. [Accessed: 12 Feb. 2019]

Zhao, Y. and Chua, D.K., 2003. Relationship between productivity and non value-adding activities. In Proceeding of the 11th annual conference of the international group for lean construction, Blacksburg, Virginia, USA. 